\title{
Biologically Inspired Synthesis Route to Three-Dimensionally Structured Inorganic Thin Films
}

\author{
Birgit Schwenzer ${ }^{1,2}$ and Daniel E. Morse ${ }^{1,2,3}$ \\ ${ }^{1}$ Institute for Collaborative Biotechnologies, University of California, Santa Barbara, CA 93106-5100, USA \\ ${ }^{2}$ California NanoSystems Institute, University of California, Santa Barbara, CA 93106-5100, USA \\ ${ }^{3}$ Department of Molecular Cellular and Developmental Biology, University of California, Santa Barbara, \\ CA 93106-9610, USA
}

Correspondence should be addressed to Prof. Daniel E. Morse, d_morse@lifesci.ucsb.edu

Received 2 October 2007; Accepted 26 December 2007

Recommended by Ping Xiao

Inorganic thin films (hydroxide, oxide, and phosphate materials) that are textured on a submicron scale have been prepared from aqueous metal salt solutions at room temperature using vapor-diffusion catalysis. This generic synthesis approach mimics the essential advantages of the catalytic and structure-directing mechanisms observed for the formation of silica skeletons of marine sponges. Chemical composition, crystallinity, and the three-dimensional morphology of films prepared by this method are extremely sensitive to changes in the synthesis conditions, such as concentrations, reaction times, and the presence and nature of substrate materials. Focusing on different materials systems, the reaction mechanism for the formation of these thin films and the influence of different reaction parameters on the product are explained.

Copyright (C) 2008 B. Schwenzer and D. E. Morse. This is an open access article distributed under the Creative Commons Attribution License, which permits unrestricted use, distribution, and reproduction in any medium, provided the original work is properly cited.

\section{INTRODUCTION}

Nanostructured thin films as well as thin films with no surface texture are currently used for many applications such as electro-optical devices [1], batteries [2], solar cell technology [3], and gas sensors [4]. These applications require high purity, defect-free materials. The use of metal organic chemical vapor deposition (MOCVD), molecular-beam epitaxy (MBE), or liquid-phase epitaxy (LPE) techniques represents the state-of-the-art fabrication processes for such highquality semiconductor thin films.

However, in recent years, lower-cost approaches to fabricate these films have emerged, among them hydrothermal [5] and electrochemical [6] synthesis methods. In addition, synthesis techniques that mimic biomineralization processes have received much attention because of the inherently benign and malleable conditions under which biominerals are produced. An increasing number of research groups have been studying biomimetic [7] or biologically inspired [8] pathways towards preparation of semiconductor materials in the past few years using biological principles of materials formation.
Biomineralization, including the formation of bones, teeth, shells, or the silica skeletons of marine sponges, takes place in vivo under ambient conditions. These biomineralization processes often produce highly ordered structures on the nanoscopic as well as the macroscopic scale, and generally nano- or micrometer-sized defects within these structures do not propagate, but are corrected on a short-range scale. The lessons learned from these biomimetic systems follow a general model $[9,10]$ : the reaction environment is anisotropically preorganized; this provides a framework from which the material can grow in an anisotropic manner. Kinetic control is imposed at the stage of nucleation, typically at an interface in the reaction environment, by closely controlling the supply of molecular precursor chemicals. In addition, crystal growth is vectorially regulated by a template, as seen both in natural systems [11-13] and artificial systems such as those based on virus protein coats [14], ferritin-like cage proteins $[14,15]$, and others [16].

Based on previous research in our group on silicatein (for silica protein) $[13,17,18]$, an enzymatic biocatalyst discovered in the biologically fabricated needles of silica made by a sponge (Tethya Aurantia), we used these biomimetic 
concepts for the development of a bioinspired synthesis route to nanostructured inorganic materials.

We observed that silicification in Tethya Aurantia is controlled by occluded protein filaments (silicateins) that serve as both templates and catalysts for the deposition of opal-like $\mathrm{SiO}_{2}$ [17-19]. In vitro experiments with isolated silicatein filaments yielded $\mathrm{SiO}_{2}$ nanoparticles similar to those formed in vivo, when the proteins were exposed to silicon tetraethoxide (TEOS) [18]. Recognizing silicatein to be a specialized member of the superfamily of hydrolytic enzymes $[17,18]$, Zhou et al. used site-directed mutagenesis to confirm the proposition that the sidechains of two specific amino acids, serine and histidine, play an essential role as partners in the catalytically active center of silicatein [19]. Based on these findings, the following mechanism for the formation of $\mathrm{SiO}_{2}$ was proposed [18]: resulting from the close proximity of the hydroxyl group of the serine, the hydrogen atom of this functional group becomes a bridging hydrogen atom linking the oxygen atom of the hydroxyl group and the nitrogen atom in the 3 positions of the imidazole ring on the histidine. This partial withdrawal of the proton leads to an increased nucleophilicity of the oxygen atom on the serine, facilitating a nucleophilic addition onto the electron-deficient silicon center of TEOS. An $\mathrm{EtO}^{-}$group is cleaved from the TEOS precursor, reacting with the electron-deficient bridging hydrogen to form $\mathrm{EtOH}$, and the addition of a water molecule then initiates hydrolysis to yield silanol, with restoration of the enzyme's catalytic center with its $-\mathrm{CH}_{2}-\mathrm{O} \cdots \mathrm{H} \cdot \cdots \mathrm{N}-$ bond. Subsequently either further hydrolysis takes place, or several silicon alkoxide molecules react via condensation to form $\mathrm{SiO}_{2}$ as the final product [18].

Mimicking this hydrolysis/condensation mechanism with its $-\mathrm{CH}_{2}-\mathrm{O} \cdots \mathrm{H} \cdot \cdots \mathrm{N}$ - sequence as the reactive center for catalysis, silica, silsesquioxanes, and metal oxide materials has been prepared using block copolypeptides of the essential catalytic amino acids [20] or small functionalized molecules [21] in an effort to remove the biomolecule from the process. In a further translation step, self-assembled monolayers (SAMs) of suitable hydroxyl- and imidazole-terminated molecules have been patterned on gold-coated silicon wafers [22]. Similarly, the same catalytic activity has been achieved by functionalizing gold nanoparticles with the respective surface coating to mimic the catalytic center of silicatein [23]. While these approaches were successful for the preparation of a variety of metal oxide materials, such as $\mathrm{TiO}_{2}$ [24] and $\mathrm{Ga}_{2} \mathrm{O}_{3}$ [25], the use of an organic template to direct synthesis is not feasible for device applications due to the contamination of the end product with the remnants of the organic template. Removing the organic elements from the process would alleviate this source of contamination and can potentially yield high-purity materials.

Translating these biomimetic systems further to achieve carbon-free reaction conditions, we recently reported a kinetically-controlled vapor-diffusion catalysis method as a biologically-inspired synthesis approach to hierarchicallystructured inorganic thin film preparation [26-29]. This method uses the principles of slow catalysis and vectorial control to achieve anisotropic, kinetically-controlled reaction conditions. However, unlike the previously mentioned approaches, the aqueous reaction solution and the gaseous catalyst ensure an extremely low level of contamination for this general method to fabricate metal oxide, hydroxide, and phosphate thin films. Other groups [30, 31] have reported the same type of structured thin films or nucleation on substrates using chemical bath deposition (CBD). In contrast to our work, substrates are essential in those methods to nucleate the films, and in some cases organic solvents are used as part of the precursor-containing solution. We here summarize and cross-link previously reported results from our group and others, and describe in more detail the mechanism for the formation of substrate-free, unsupported films and the influence of different reaction parameters on the resulting thin film products.

\section{VAPOR-DIFFUSION CATALYSIS}

A wide variety of inorganic materials in thin film morphology have been prepared using vapor-diffusion catalysis [2629] or CBD [30, 32]. For growth on substrates, a heterogeneous nucleation mechanism has been established. Figure 1 shows an illustration of the experimental setup for a typical vapor-diffusion catalysis reaction.

In the vapor-diffusion catalysis method, a gaseous catalyst from an external source is diffused into an aqueous metal salt solution (Figure 1(a)). Adding the catalyst as a gas at low concentrations by vapor-diffusion instead of adjusting the $\mathrm{pH}$ homogeneously in solution leads to an anisotropic reaction environment that is temporally and spatially controlled by the rate of diffusion. In the case illustrated and described above, a $\mathrm{pH}$ gradient, decreasing from the vapor-liquid interface towards the bottom of the reaction vessel, is created.

Rather than introducing the gaseous catalyst into the closed reaction environment by connecting it to a gas cylinder, we rely on the in situ formation of a liquid/vapor solution equilibrium from a suitable source to saturate the reaction chamber with gaseous catalyst. For example, an aqueous $\mathrm{NH}_{4} \mathrm{OH}$ solution is used to yield an $\mathrm{NH}_{3}$ atmosphere (Figure 1(a)), which serves as the catalyst for the reactions discussed here. Employing an environment that from the beginning is completely saturated with the catalytic gas would significantly accelerate the initial rates of hydrolysis, condensation and nucleation, and therefore would not allow the maximum benefits of slow catalysis that we achieve through vapor-diffusion catalysis as opposed to, for example, hydrothermal reactions.

The slow diffusion and catalysis allow for very localized formation of nucleation crystallites close to the meniscus of the reaction solution during the first minutes of the synthesis. Measurements of $\mathrm{pH}$ changes at the vapor-liquid interface have confirmed that the increase in $\mathrm{pH}$, that is, $\left[\mathrm{OH}^{-}\right]$ concentration, can be correlated with the formation of nucleation crystallites [27]. Figures 1(b)-1(d) show SEM images of $\mathrm{Co}_{5}(\mathrm{OH})_{8}\left(\mathrm{NO}_{3}\right)_{2} \cdot 2 \mathrm{H}_{2} \mathrm{O}$ films at various stages of formation. After 15 minutes, clusters that seem to originate from discrete island nucleation can be observed. The shape of the crystallites growing into the aqueous reaction solution (indicated by the arrow in Figure 1(b)) is similar to the spindleshaped hexagonal crystallites Yamabi and Imai [31] observed 


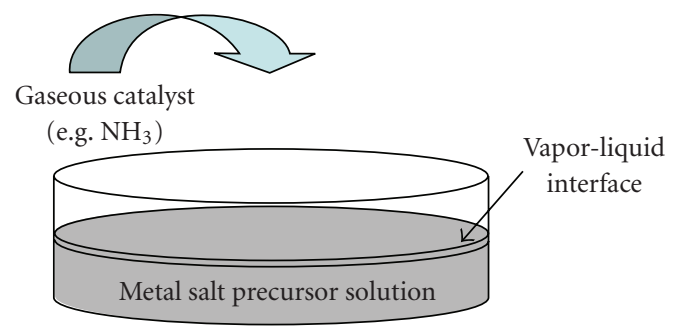

(a)

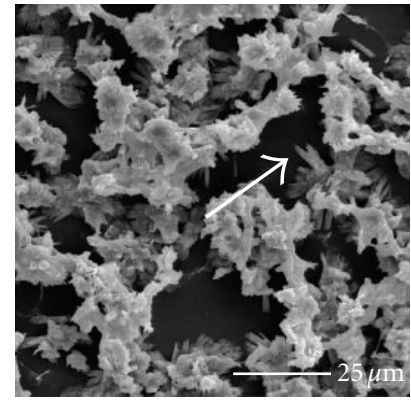

(b)

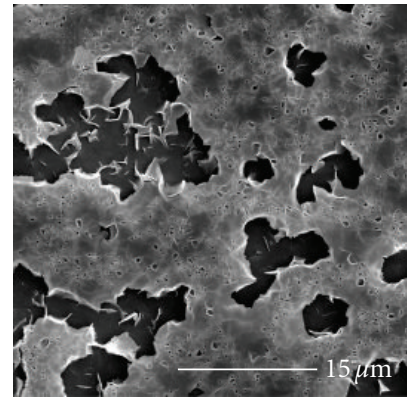

(c)

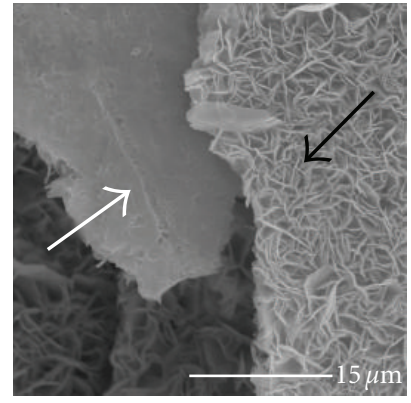

(d)

FIGURE 1: (a) Schematic illustration of the vapor-diffusion catalysis method for unsupported film formation from aqueous metal salt solutions; SEM images of the growth of $\mathrm{Co}_{5}(\mathrm{OH})_{8}\left(\mathrm{NO}_{3}\right)_{2} \cdot 2 \mathrm{H}_{2} \mathrm{O}$ from $0.1 \mathrm{M} \mathrm{Co}\left(\mathrm{NO}_{3}\right)_{2}$ solution showing (b) noncontinuous network of partially fused $\mathrm{Co}_{5}(\mathrm{OH})_{8}\left(\mathrm{NO}_{3}\right)_{2} \cdot 2 \mathrm{H}_{2} \mathrm{O}$ nucleation islands after 15 minute reaction time, (c) extended network of further fused $\mathrm{Co}_{5}(\mathrm{OH})_{8}\left(\mathrm{NO}_{3}\right)_{2} \cdot 2 \mathrm{H}_{2} \mathrm{O}$ nucleation islands after 30-minute reaction time; and (d) fully condensed structured $\mathrm{Co}_{5}(\mathrm{OH})_{8}\left(\mathrm{NO}_{3}\right)_{2} \cdot 2 \mathrm{H}_{2} \mathrm{O}$ thin films after 60-minute reaction time.

for their CBD growth on glass, Si, and other substrates. Some fusion of these crystallites, originating from their nucleation centers rather than the protruding crystalline spikes, can already be seen. Thirty minutes after the start of the reaction, the formation of a continuous although still porous plane connecting the individual crystallites has progressed significantly (Figure $1(\mathrm{c})$ ). This plane will eventually form the backplane of the structured film, thickening to $\sim 1.5 \mu \mathrm{m}$ [26] and incorporating the original spindle-like crystallites into the base of the film. For the formation of structured $\mathrm{Co}_{5}(\mathrm{OH})_{8}\left(\mathrm{NO}_{3}\right)_{2} \cdot 2 \mathrm{H}_{2} \mathrm{O}$ thin films from a $0.1 \mathrm{M} \mathrm{Co}\left(\mathrm{NO}_{3}\right)_{2}$ solution, the fusion of the backplane is complete after $\sim 60$ minutes; simultaneously during this time, plates with a thickness of $\sim 30-50 \mathrm{~nm}$ [26] formed protruding orthogonally from the continuous backplane oriented into the aqueous reaction solution (Figure 1(d)). The arrows in Figure 1(d) indicate the backplane (white arrow) and the nanostructured side of the material (black arrow), respectively.

Hydrothermal methods, that rely on the in situ formation of either one of the precursor materials or the reaction catalyst, similarly achieve a temporally controlled slow crystal formation [30, 33]. For example, thermal decomposition of urea [30] or hexamethylenetetramine (HMT) [33] has been used to liberate a basic catalyst. However, this approach does not make use of spatial control of nucleation. The reaction environment in hydrothermal synthesis is isotropic, with homogeneous nucleation in solution competing with heterogeneous nucleation on the supplied substrate.

The density, size, and shape of the structures protruding from the continuous backplane of inorganic films pre- pared using vapor-diffusion catalysis can be modified without the use of organic surfactants or growth inhibitors. We have shown this control to depend on the type and concentration of the metal salt precursor and gaseous catalyst and on the reaction time $[26,27]$.

As can be seen in Figure 2, the morphology and shape of the nanostructured features and their 3-dimensionality vary depending on the chemical composition of the final products. Both materials $(\mathrm{ZnO}$, Figure 2(a); $\mathrm{Zn}_{5}(\mathrm{OH})_{8}\left(\mathrm{NO}_{3}\right)_{2} \cdot 2 \mathrm{H}_{2} \mathrm{O}$, Figure 2(b)) were prepared by vapor-diffusion catalysis, diffusing ammonia into an aqueous $\mathrm{Zn}\left(\mathrm{NO}_{3}\right)_{2}$ solution under differing conditions of precursor concentration and reaction time [26, 27].

The nanostructured $\mathrm{ZnO}$ film seen in Figure 2(a) was crystallized by vapor-diffusion catalysis from a $0.05 \mathrm{M}$ $\mathrm{Zn}\left(\mathrm{NO}_{3}\right)_{2}$ solution, whereas the $\mathrm{Zn}\left(\mathrm{NO}_{3}\right)_{2}$ concentration used to obtain the structured $\mathrm{Zn}_{5}(\mathrm{OH})_{8}\left(\mathrm{NO}_{3}\right)_{2} \cdot 2 \mathrm{H}_{2} \mathrm{O}$ film (Figure 2(b)) was twice as high. With the slower nucleation rate, hexagonal $\mathrm{ZnO}$ is formed [27]. In contrast, the rate of initial nucleation is faster when higher concentrations of metal salt precursor solution and gaseous catalyst are used, leading to the incorporation of anionic counterions from the precursor material. To accommodate the incorporation of bulky $\mathrm{NO}_{3}^{-}$ions, the films that are formed from the higher concentration of $\mathrm{Zn}\left(\mathrm{NO}_{3}\right)_{2}$ precursor do not crystallize in a close-packed hexagonal crystal structure, instead a layered hydrotalcite-like structure is formed [26, 34]. This interesting structure consists of $\mathrm{Zn}^{2+}$ containing layers, that carry a net positive charge from the incorporation of tetrahedrally coordinated $\mathrm{Zn}^{2+}$ ions into the crystal structure of otherwise 


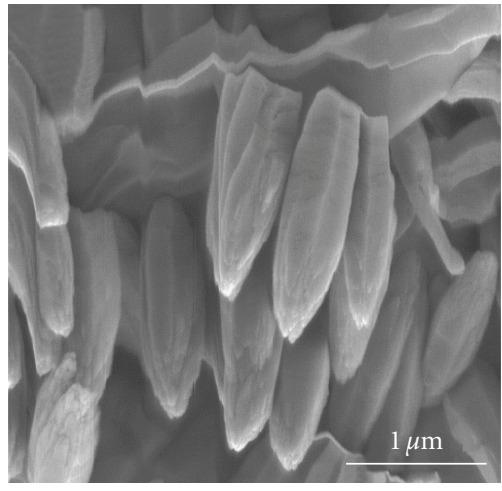

(a)

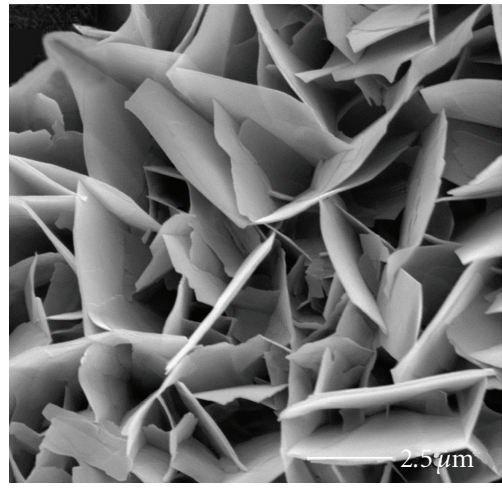

(b)

FIGURE 2: (a) High-resolution SEM image of the nanostructures protruding from a ZnO thin film prepared by low-concentration vapordiffusion from a $0.05 \mathrm{M} \mathrm{Zn}\left(\mathrm{NO}_{3}\right)_{2}$ solution. Reprinted by permission from Journal of the American Chemical Society, vol. 128, no. 31, pp. 10276-10280, 2006(C)American Chemical Society. (b) SEM image of the nanostructures protruding from a $\mathrm{Zn}_{5}\left(\mathrm{OH}_{8}\left(\mathrm{NO}_{3}\right)_{2} \cdot 2 \mathrm{H}_{2} \mathrm{O}\right.$ thin film prepared by vapor-diffusion from a $0.1 \mathrm{M} \mathrm{Zn}\left(\mathrm{NO}_{3}\right)_{2}$ solution.

octahedrally coordinated ions [34]. The layers are held together by the intercalation of $\mathrm{NO}_{3}^{-}$counterions, resulting in a $\mathrm{Zn}^{2+}: \mathrm{NO}_{3}^{-}$ratio of $5: 2$. The overall crystal structure of this layered compound is monoclinic [35]. We believe that the difference in nanostructured morphologies of the two materials is a direct consequence of the difference in their crystal structures. Further experiments to confirm this hypothesis are in progress.

To study the effect on crystallinity and morphology of films prepared using vapor-diffusion catalysis when substrates are introduced into the reaction system, different substrates were used as templates for the growth of thin films from aqueous $\mathrm{Zn}\left(\mathrm{NO}_{3}\right)_{2}$ solutions [28]. Unlike the results of CBD [32], again the reaction solution only contained the metal salt precursor and the catalyst was added by diffusion as a gaseous medium. The reaction solution was not stirred during the synthesis to not disturb the anisotropic reaction environment.

Two examples of structured thin films grown from the same $0.1 \mathrm{M} \mathrm{Zn}\left(\mathrm{NO}_{3}\right)_{2}$ solution can be seen in Figure 3. The observed difference in morphology in this case is not due to different reaction conditions but to nucleation sites provided by different substrates that offer a more or less suitably lattice-matched base for $\mathrm{ZnO}$ [28]. The film in Figure 3(a) has been grown on an amorphous glass substrate and consists of amorphous $\mathrm{Zn}_{5}(\mathrm{OH})_{8}\left(\mathrm{NO}_{3}\right)_{2} \cdot 2 \mathrm{H}_{2} \mathrm{O}$. The 3-dimensional structure of the film with its individual plates protruding from the backplane attached to the nucleation surface closely resembles that of the unsupported $\mathrm{Zn}_{5}(\mathrm{OH})_{8}\left(\mathrm{NO}_{3}\right)_{2} \cdot 2 \mathrm{H}_{2} \mathrm{O}$ films (Figure $2(\mathrm{~b})$ ). When polished (0001) oriented epitaxially grown $\mathrm{ZnO}$ was used as substrate, the difference of this substrate in crystallinity, crystallographic lattice matching with respect to $\mathrm{Zn}_{5}(\mathrm{OH})_{8}\left(\mathrm{NO}_{3}\right)_{2} \cdot 2 \mathrm{H}_{2} \mathrm{O}$ and $\mathrm{ZnO}$, and the polycrystalline versus epitaxially grown surface morphology evidently suppressed the nucleation of $\mathrm{Zn}_{5}(\mathrm{OH})_{8}\left(\mathrm{NO}_{3}\right)_{2} \cdot 2 \mathrm{H}_{2} \mathrm{O}$ in favor of the formation of a 3-dimensional network of highly crystalline $\mathrm{ZnO}$ [28]. These results indicate that substrates of dif- ferent chemical composition and degrees of crystallinity can be used to induce the preferential growth of specific materials and govern the morphology of the resulting thin films. Furthermore, the integrability of our vapor-diffusion synthesis method into existing manufacturing processes such as MOCVD or MBE has been demonstrated, and these results confirm its potential use as a low-cost alternative to these fabrication methods.

Another way to modify the chemical composition of structured thin films prepared by vapor-diffusion catalysis is to supply different counterions to be incorporated into the crystal structure. This method allows subtle changes to be made in the crystal structure, such as replacing the anions that hold together the positively charged metal ion sheets in hydrotalcite-like structures, and to thereby change the lattice spacing along the $c$-direction within the polycrystalline material. For example, $\mathrm{Co}_{5}(\mathrm{OH})_{8}\left(\mathrm{NO}_{3}\right)_{2} \cdot 2 \mathrm{H}_{2} \mathrm{O}$, $\mathrm{Co}_{5}(\mathrm{OH})_{8} \mathrm{SO}_{4} \cdot 2 \mathrm{H}_{2} \mathrm{O}$, and $\mathrm{Co}_{5}(\mathrm{OH})_{8} \mathrm{Cl}_{2} \cdot 3 \mathrm{H}_{2} \mathrm{O}$ have been prepared from their respective metal nitrate, sulfate, and chloride salts, with diffraction analyses confirming changes in the lattice spacing proportional to the counterion diameter [26]. While the rates of formation of the hierarchically structured films of these cobalt-containing hydrotalcite-like materials vary slightly, their overall morphologies are very similar. This is another indication that similar crystal structures favor the formation of similar types of nanostructures that grow from the continuous backplane of the thin film material.

The chemical composition of thin films can be changed more significantly, when additional anions are added to the reaction solution. If the incorporation of these anions is more favorable than the formation of hydroxide or oxide materials, different types of inorganic materials can be formed using the vapor-diffusion catalysis method. As one example, we have identified synthesis conditions that favor the formation of metal phosphate thin films under very similar conditions than have been used to prepare the metal oxide or hydroxide films $[26,29]$. Thus, we found that the addition of $\left(\mathrm{NH}_{4}\right)_{2} \mathrm{HPO}_{4}$ to aqueous chromium or manganese salt 


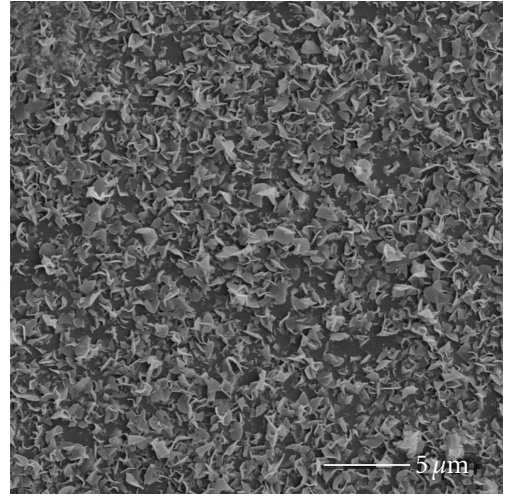

(a)

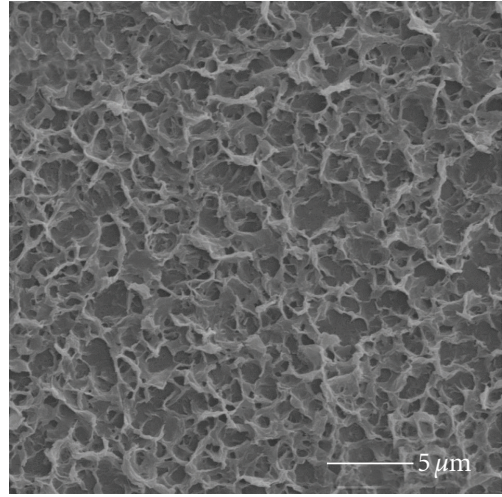

(b)

FIGURE 3: SEM images of thin films grown on different substrates from an aqueous $0.1 \mathrm{M} \mathrm{Zn}\left(\mathrm{NO}_{3}\right)_{2}$ solution by vapor-diffusion catalysis over the course of 6 hours: (a) $\mathrm{Zn}_{5}(\mathrm{OH})_{8}\left(\mathrm{NO}_{3}\right)_{2} \cdot 2 \mathrm{H}_{2} \mathrm{O}$ on amorphous glass; (b) $\mathrm{ZnO}$ on the (0001) face of epitaxially grown $\mathrm{ZnO}$.

solutions leads to the formation of $\mathrm{CrPO}_{4} \cdot 6 \mathrm{H}_{2} \mathrm{O}$ [29] and $\mathrm{Mn}_{3}\left(\mathrm{PO}_{4}\right)_{2} \cdot 7 \mathrm{H}_{2} \mathrm{O}$ [26], respectively. These films also display the same general morphology as described above, with submicron-scale structures protruding from the side of the continuous film that had been facing the aqueous solution during the 18-24 hour reaction time.

\section{CONCLUSION}

A generic low-temperature method, for the preparation of structured inorganic metal oxide, hydroxide and phosphate films, has been introduced. The underlying biomimetic principles of materials formation have been reviewed, and their importance has been discussed. Because the chemical composition, crystallinity and morphology of the films, is very susceptible to changes in the reaction environment, this opens many possibilities to tailor the properties of films prepared by this environmentally benign vapor-diffusion catalysis. The method allows the synthesis of freestanding, unsupported films as well as film growth on substrates. We have proposed a nucleation sequence for the formation of structured films grown by this kinetically-controlled synthesis approach, and discussed previously reported results, cross-linking the findings and discussing different possibilities for modification of selected aspects of thin film growth.

In summary, we have reviewed a generic synthesis approach for low-cost, low-temperature fabrication of structured inorganic metal oxide, hydroxide and phosphate films. The integrability of the vapor-diffusion catalysis method into existing manufacturing processes such as MOCVD or MBE has been demonstrated.

\section{ACKNOWLEDGMENTS}

This work was supported in part by grants from the U.S. Department of Energy (DEFG03-02ER46006); DARPA (HR0011-04-1-0059); the U.S. Army Research Office through Grant no. DAAD19-03-D-0004 to the Institute for Collaborative Biotechnologies; and the MRSEC Pro- gram (Award no. DMR05-20415) of the National Science Foundation (UCSB Materials Research Laboratory).

\section{REFERENCES}

[1] Y. A. Vlasov, X.-Z. Bo, J. C. Sturm, and D. J. Norris, "On-chip natural assembly of silicon photonic bandgap crystals," $\mathrm{Na}$ ture, vol. 414, no. 6861, pp. 289-293, 2001.

[2] L. Kavan, M. Kalbáč, M. Zukalová, et al., "Lithium storage in nanostructured $\mathrm{TiO}_{2}$ made by hydrothermal growth," Chemistry of Materials, vol. 16, no. 3, pp. 477-485, 2004.

[3] M. C. Lux-Steiner, A. Ennaoui, C.-H. Fischer, et al., "Processes for chalcopyrite-based solar cells," Thin Solid Films, vol. 361362, pp. 533-539, 2000.

[4] S. Marian, D. Tsiulyanu, T. Marian, and H.-D. Liess, "Chalcogenide-based chemical sensors for atmospheric pollution control," Pure and Applied Chemistry, vol. 73, no. 12, pp. 2001-2004, 2001.

[5] J. H. Kim, E.-M. Kim, D. Andeen, D. Thomson, S. P. DenBaars, and F. F. Lange, "Growth of heteroepitaxial $\mathrm{ZnO}$ thin films on $\mathrm{GaN}$-buffered $\mathrm{Al}_{2} \mathrm{O}_{3}$ (0001) substrates by low-temperature hydrothermal synthesis at $90^{\circ} \mathrm{C}$," Advanced Functional Materials, vol. 17, no. 3, pp. 463-471, 2007.

[6] D. M. Soolaman and H.-Z. Yu, "Monolayer-directed electrodeposition of oxide thin films: surface morphology versus chemical modification," Journal of Physical Chemistry $C$, vol. 111, no. 38, pp. 14157-14164, 2007.

[7] Q. Dong, H. Su, W. Cao, D. Zhang, Q. Guo, and F. Zhang, "Assembly and formation of biomorphic tin dioxide by a biomimetic sol-gel approach involving glycoprotein," European Journal of Inorganic Chemistry, vol. 2007, no. 16, pp. 2265-2273, 2007.

[8] M. A. Stroscio and M. Dutta, "Biologically-inspired chemically-directed self-assembly of semiconductor quantum-dotbased systems: phonon-hole scattering in DNA bound to DNA-quantum-dot complexes," International Journal of High Speed Electronics and Systems, vol. 16, no. 2, pp. 659-668, 2006.

[9] S. Mann, Biomineralization: Principles and Concepts in Bioinorganic Materials Chemistry, Oxford University Press, Oxford, UK, 2001.

[10] S. Mann, Biomimetic Materials Chemistry, VCH, New York, NY, USA, 1996. 
[11] G. Falini, S. Albeck, S. Weiner, and L. Addadi, "Control of aragonite or calcite polymorphism by mollusk shell macromolecules," Science, vol. 271, no. 5245, pp. 67-69, 1996.

[12] X. Su, A. M. Belcher, C. M. Zaremba, D. E. Morse, G. D. Stucky, and A. H. Heuer, "Structural and microstructural characterization of the growth lines and prismatic microarchitecture in red abalone shell and the microstructures of abalone "flat pearls"," Chemistry of Materials, vol. 14, no. 7, pp. 31063117, 2002.

[13] H. Cölfen and S. Mann, "Higher-order organization by mesoscale self-assembly and transformation of hybrid nanostructures," Angewandte Chemie International Edition, vol. 42, no. 21, pp. 2350-2365, 2003.

[14] C. Mao, D. J. Solis, B. D. Reiss, et al., "Virus-based toolkit for the directed synthesis of magnetic and semiconducting nanowires," Science, vol. 303, no. 5655, pp. 213-217, 2004.

[15] M. Allen, D. Willits, M. Young, and T. Douglas, "Constrained synthesis of cobalt oxide nanomaterials in the 12-subunit protein cage from Listeria innocua," Inorganic Chemistry, vol. 42, no. 20, pp. 6300-6305, 2003.

[16] H. Aldersey-Williams, "Towards biomimetic architecture," Nature Materials, vol. 3, no. 5, pp. 277-279, 2004.

[17] K. Shimizu, J. Cha, G. D. Stucky, and D. E. Morse, "Silicatein $\alpha$ : cathepsin L-like protein in sponge biosilica," Proceedings of the National Academy of Sciences of the United States of America, vol. 95, no. 11, pp. 6234-6238, 1998.

[18] J. N. Cha, K. Shimizu, Y. Zhou, et al., "Silicatein filaments and subunits from a marine sponge direct the polymerization of silica and silicones in vitro," Proceedings of the National Academy of Sciences of the United States of America, vol. 96, no. 2, pp. 361-365, 1999.

[19] Y. Zhou, K. Shimizu, J. N. Cha, G. D. Stucky, and D. E. Morse, "Efficient catalysis of polysiloxane synthesis by silicatein $\alpha$ requires specific hydroxy and imidazole functionalities," Angewandte Chemie International Edition, vol. 38, no. 6, pp. 779782, 1999.

[20] J. N. Cha, G. D. Stucky, D. E. Morse, and T. J. Deming, "Biomimetic synthesis of ordered silica structures mediated by block copolypeptides," Nature, vol. 403, no. 6767, pp. 289-292, 2000.

[21] K. M. Roth, Y. Zhou, W. Yang, and D. E. Morse, "Bifunctional small molecules are biomimetic catalysts for silica synthesis at neutral pH," Journal of the American Chemical Society, vol. 127, no. 1, pp. 325-330, 2005.

[22] D. Kisailus, Q. Truong, Y. Amemiya, J. C. Weaver, and D. E. Morse, "Self-assembled bifunctional surface mimics an enzymatic and templating protein for the synthesis of a metal oxide semiconductor," Proceedings of the National Academy of Sciences of the United States of America, vol. 103, no. 15, pp. 56525657, 2006.

[23] D. Kisailus, M. Najarian, J. C. Weaver, and D. E. Morse, "Functionalized gold nanoparticles mimic catalytic activity of a polysiloxane-synthesizing enzyme," Advanced Materials, vol. 17, no. 10, pp. 1234-1239, 2005.

[24] J. L. Sumerel, W. Yang, D. Kisailus, J. C. Weaver, J. H. Choi, and D. E. Morse, "Biocatalytically templated synthesis of titanium dioxide," Chemistry of Materials, vol. 15, no. 25, pp. 4804-4809, 2003.

[25] D. Kisailus, J. H. Choi, J. C. Weaver, W. Yang, and D. E. Morse, "Enzymatic synthesis and nanostructural control of gallium oxide at low temperature," Advanced Materials, vol. 17, no. 3, pp. 314-318, 2005.

[26] B. Schwenzer, K. M. Roth, J. R. Gomm, M. Murr, and D. E. Morse, "Kinetically controlled vapor-diffusion synthesis of novel nanostructured metal hydroxide and phosphate films using no organic reagents," Journal of Materials Chemistry, vol. 16, no. 4, pp. 401-407, 2006.

[27] D. Kisailus, B. Schwenzer, J. Gomm, J. C. Weaver, and D. E. Morse, "Kinetically controlled catalytic formation of zinc oxide thin films at low temperature," Journal of the American Chemical Society, vol. 128, no. 31, pp. 10276-10280, 2006.

[28] B. Schwenzer, J. R. Gomm, and D. E. Morse, "Substrateinduced growth of nanostructured zinc oxide films at room temperature using concepts of biomimetic catalysis," Langmuir, vol. 22, no. 24, pp. 9829-9831, 2006.

[29] J. R. Gomm, B. Schwenzer, and D. E. Morse, "Textured films of chromium phosphate synthesized by low-temperature vapor diffusion catalysis," Solid State Sciences, vol. 9, no. 5, pp. 429$431,2007$.

[30] E. Hosono, S. Fujihara, I. Honma, and H. Zhou, "Fabrication of morphology and crystal structure controlled nanorod and nanosheet cobalt hydroxide based on the difference of oxygensolubility between water and methanol, and conversion into $\mathrm{Co}_{3} \mathrm{O}_{4}$," Journal of Materials Chemistry, vol. 15, no. 19, pp. 1938-1945, 2005.

[31] S. Yamabi and H. Imai, "Growth conditions for wurtzite zinc oxide films in aqueous solutions," Journal of Materials Chemistry, vol. 12, no. 12, pp. 3773-3778, 2002.

[32] G. Hodes, "Semiconductor and ceramic nanoparticle films deposited by chemical bath deposition," Physical Chemistry Chemical Physics, vol. 9, no. 18, pp. 2181-2196, 2007.

[33] T. Zhang, W. Dong, M. Keeter-Brewer, S. Konar, R. N. Njabon, and Z. R. Tian, "Site-specific nucleation and growth kinetics in hierarchical nanosyntheses of branched $\mathrm{ZnO}$ crystallites," Journal of the American Chemical Society, vol. 128, no. 33, pp. 10960-10968, 2006.

[34] W. Stählin and H. R. Oswald, "The crystal structure of zinc hydroxide nitrate, $\mathrm{Zn}_{5}(\mathrm{OH})_{8}\left(\mathrm{NO}_{3}\right)_{2} \cdot 2 \mathrm{H}_{2} \mathrm{O}$," Acta Crystallographica. Section B, vol. 26, no. 6, pp. 860-863, 1970.

[35] JCPDS file \# 01-072-0627. 

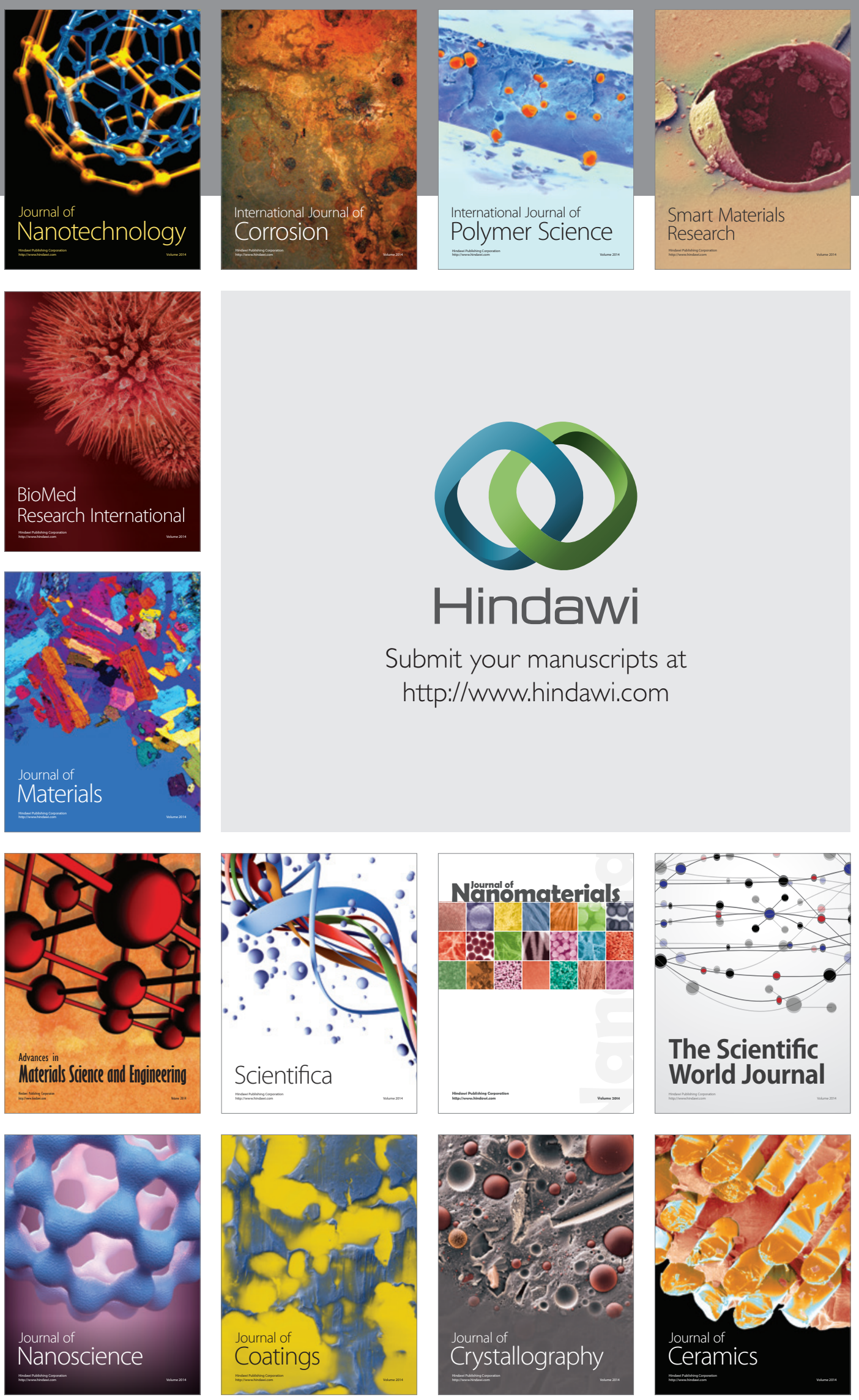

The Scientific World Journal

Submit your manuscripts at

http://www.hindawi.com

\section{World Journal}

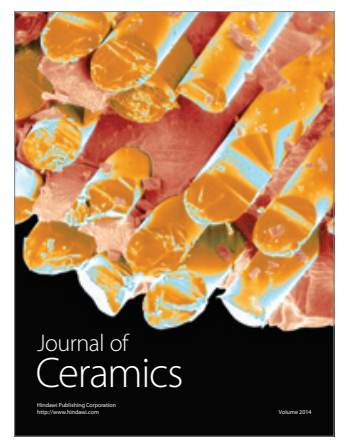

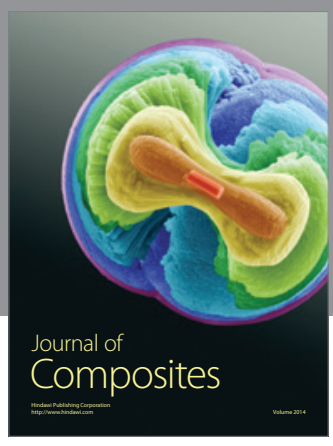
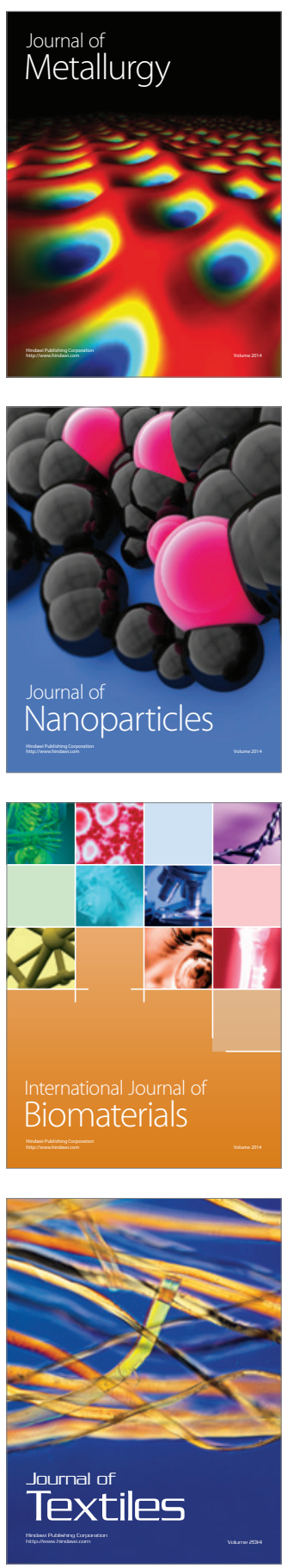